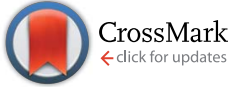

Cite this: RSC Adv., 2017, 7, 201

Received 7th October 2016

Accepted 24th November 2016

DOI: $10.1039 / c 6 r a 24870$ e

www.rsc.org/advances

\section{Electrospun three-layered polymer nanofiber- based porous carbon nanotubes for high-capacity energy storage $\uparrow$}

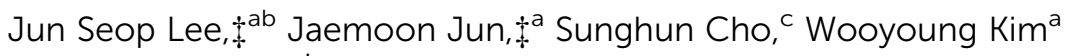 \\ and Jyongsik Jang*a
}

\begin{abstract}
Recently, carbon nanomaterials are attractive for various applications owing to the benefits derived from their high electrical conductivity, chemical stability and large surface to volume ratio. However, the fabrication process of carbon nanomaterials is complicated and exhibits low productivity. Here we report the facile one-pot synthesis of highly porous 1D carbon nanotubes based on three-layered polymer nanofibers by using a dual-nozzle co-electrospinning technique to apply to an energy storage device. Specific capacitance $\left(C_{G}\right)$ of the porous carbon nanotube-based electrode is $401 \mathrm{~F} \mathrm{~g}^{-1}$, which is larger than that of the other carbon nanomaterials. Furthermore, the porous carbon nanotube exhibits excellent rate capability and cycle stability due to micro-/mesopores in the carbon structure enhancing the active surface area between carbon and the ions of the electrolytes. This unique fabrication technique is an effective approach for forming large scale highly porous carbon nanomaterials for diverse electrochemical applications.
\end{abstract}

\section{Introduction}

Carbon-based nanomaterials have led to the development of various electrical and electrochemical device applications on account of their favorable uniform structure, high electric conductivity and chemical stability. ${ }^{1-5}$ Among the different morphologies of carbons, one-dimensional (1D) carbon nanomaterials have received considerable attention owing to their unique characteristics that are high surface to volume ratio and enhanced electrical conductivity. ${ }^{6-10}$ Therefore, a lot of researches have been conducted to fabricate 1D carbon nanomaterial with well controlled chemical composition and morphology using self-assembly solvothermal synthesis, chemical vapor deposition, and nanocasting. ${ }^{11-15}$ However, there are several limitations of these synthesis that are rigid reaction conditions, high cost, and complicated synthetic steps. ${ }^{\mathbf{1 4}, \mathbf{1 5}}$ One of the alternative 1D nanostructure synthetic process, electrospinning is an effective and convenient method

${ }^{a}$ School of Chemical and Biological Engineering, College of Engineering, Seoul National University, 599 Gwanangno, Gwanakgu, Seoul, 151-742, Korea. E-mail: jsjang@plaza.snu.ac.kr; Fax: +82-2-888-1604; Tel: +82-2-880-7069

${ }^{b}$ Institute for Molecular Engineering, University of Chicago, 5640 South Ellis Avenue, Chicago, IL 60637, USA

'School of Chemical Engineering, Yeungnam University, 280 Daehak-Ro, Gyeongsan 38541, Korea

$\dagger$ Electronic supplementary information (ESI) available: Apparatus of dual-nozzle co-electrospinning; CV curves of other PCNTs; galvanostatic charge/discharge curves of other PCNTs. See DOI: 10.1039/c6ra24870e

\$ These authors contributed equally to this work. to fabricate uniform and large-scale nanofibers. ${ }^{16-20}$ Especially, 1D carbon nanofibers originated from electrospinning process are increasing of interest in electrochemical devices for the following reasons: (1) the $1 \mathrm{D}$ geometry permits efficient electron transport along the longitudinal direction; $;^{21,22}$ (2) the 1D structure increases the ion flux at the interface between the active material and the electrode because of the large surface-tovolume ratio with the electrolyte and the reduced ion diffusion length. ${ }^{23,24}$ Moreover, co-electrospinning technique, using phase separated polymer solutions (i.e., PMMA/PAN, PAN/PVP, and PS/PAN), is used to produce unique structure of porous carbon nanofibers. ${ }^{25-29}$

As promising practical application of porous carbon nanostructures, supercapacitor (SC) device, one of energy storage system, is used because of predominant mechanical strength, high surface area and pores in the carbon structure. ${ }^{30-32}$ The capacitance of the SC is caused by the pore size of the carbon structure and active surface area of the electrode. In detail, micropores $(<2 \mathrm{~nm})$ enhance surface area and provide more active sites for adsorption of electrolyte, while mesopores (2$50 \mathrm{~nm}$ ) improve penetration of electrolyte in the carbon structure for high power density. ${ }^{33-35}$ In addition, macropores $(>50 \mathrm{~nm})$ are important to electrolyte transportation into the carbon electrode and ratio enhancement of electrode utilization. ${ }^{36,37}$ Therefore, hierarchical porous carbon nanofibers with micro-/mesopores are needed in SC electrode. Recently, lots of efforts have been conducted to rational design and preparation of hierarchical porous carbon nanofibers by using several template methods to improve electrochemical performance of 
SC electrode. ${ }^{38-40}$ However, the techniques using template have several limitations that are complexity and low output. ${ }^{\mathbf{4 1 , 4 2}}$ To solve these problems, further research with facile and large output is required to appreciate porous carbon nanofibers.

Herein, we report a new facile and cost-effective strategy for fabricating highly porous carbon nanotubes. A dual-nozzle coelectrospinning technique is described that can control the diameter of tube and density of micropores in the tube structure precisely. First, three-layered polymer nanofibers, composed of PMMA (first layer), PAN (second layer), and PVP (third layer), were formed using dual-nozzle co-electrospinning method. Then, highly porous carbon nanotubes, contained micro- and mesopores, were fabricated through following heat treatment. The highly porous carbon nanotubes were used as electrode materials for supercapacitors exhibited a specific capacitance of $401 \mathrm{~F} \mathrm{~g}^{-1}$, which is higher than that of pristine carbon nanotubes or other carbon nanofibers. SC electrode based on porous carbon nanotubes also exhibited not only high cycle stability but also excellent rate capability originated from inner microand mesopores in the carbon structure. To the best of our knowledge, no reports have described the manufacture of highly porous carbon nanotubes using the dual-nozzle coelectrospinning technique.

\section{Experimental section}

\subsection{Materials}

Poly(acrylonitrile) (PAN, Mw = 150 000), poly(vinylpyrrolidone) (PVP, Mw = 1300 000), and poly(methyl methacrylate) (PMMA, $\mathrm{Mw}=350$ 000) were purchased from Aldrich Chemical Co. $\mathrm{N}, \mathrm{N}$ Dimethylformamide (DMF, Aldrich) was used as the solvent in the PAN, PVP, and PMMA solutions.

\subsection{Fabrication of highly porous carbon nanotubes}

Each PAN and PVP solution was prepared by dissolving $1.0 \mathrm{~g}$ of polymer in $10 \mathrm{~mL}$ of $\mathrm{DMF}$ at $80^{\circ} \mathrm{C}$ for $1 \mathrm{~h}$ with vigorous stirring. Then, the PAN and the PVP solutions were mixed at $80^{\circ} \mathrm{C}$ for $3 \mathrm{~h}$ to fabricate outer part of electrospinning polymer solution. PMMA solution was prepared by dissolving $0.7 \mathrm{~g}$ of PMMA in $10 \mathrm{~mL}$ of $\mathrm{DMF}$ at $60{ }^{\circ} \mathrm{C}$ for $2 \mathrm{~h}$ with vigorous stirring to apply inner part of electrospinning polymer solution. The mixed polymer solution (PAN and PVP) was loaded into a syringe pump (KD Scientific, U.S.A) and then pumped through the outer part of the dual metal nozzle $(20 \mathrm{G}$ needle; inner diameter: $0.5 \mathrm{~mm}$ ). PMMA polymer solution was injected from syringe pump through the inner part of dual-nozzle $(27 \mathrm{G}$ needle; inner diameter: $0.1 \mathrm{~mm}$ ). A voltage of $15 \mathrm{kV}$ was applied between the metal nozzle and the collector. The distance between the nozzle and collector was $15 \mathrm{~cm}$ and the flow rate of syringe pumps were maintained at $5 \mu \mathrm{L} \mathrm{min}^{-1}$. The electrospun core-shell nanofibers were carbonized at $800{ }^{\circ} \mathrm{C}$ for $1 \mathrm{~h}$ in nitrogen gas flow at a heating rate of $5{ }^{\circ} \mathrm{C} \min ^{-1}$.

\subsection{Characterization and electrochemical measurement}

A JEOL 6700 was used to obtain field-emission scanning electron microscopy (FE-SEM) images. Transmission electron microscopy
(TEM) and high-resolution transmission electron microscopy (HR-TEM) images were obtained using a JEOL JEM-200CX and a JEOL JEM-3010, respectively. During sample preparation, materials diluted in ethanol were cast onto a copper grid. X-ray diffraction (XRD) was recorded using a M18XHF SRA (MAC Science Co.). A focused ion beam (FIB) system (FET Helios 650) was used to examine the fabric structure. CV/galvanostatic charge-discharge curves, electrochemical impedance spectroscopy (EIS, frequency range: $200 \mathrm{kHz}$ to $20 \mathrm{mHz}$; amplitude: $5 \mathrm{mV}$ ) and cycling stability measurements were conducted using an electrochemical workstation (ZIVE SP2).

\section{Results and discussion}

\subsection{Fabrication of highly porous carbon nanotubes}

Fig. 1a and $\mathrm{S} 1 \dagger$ illustrates the overall diagram of dual-nozzle coelectrospinning process that consists of high voltage supplier, ground, and dual-nozzle connected with different polymer solutions. To fabricate three-layered polymer nanofiber as starting material, each polymer solution was connected to dualnozzle that was PMMA (inner-nozzle) and PAN/PVP mixed solutions (outer-nozzle). In the mixed polymer solution, PVP and PAN are separated as continuous (surrounding) and discontinuous (droplet) phases owing to the incompatibility of the two polymers as a result of their intrinsic properties, in particular, their viscosity (inset of Fig. 1a). ${ }^{25,26}$ Then, the mixed PAN/PVP solution was electrospun by the outer part of the dualnozzle, while PMMA solution was electrospun through the inner nozzle onto the collector under a continuous high voltage. During electrospinning process, the shell fluid (PVP and PAN mixed solution) forms a sheath around the core fluid (PMMA solution), which entrains and stabilizes of the core fluid against break-up into droplets by this process such as the Rayleigh instability. In other words, the shell mixed polymer (PAN and

(a)

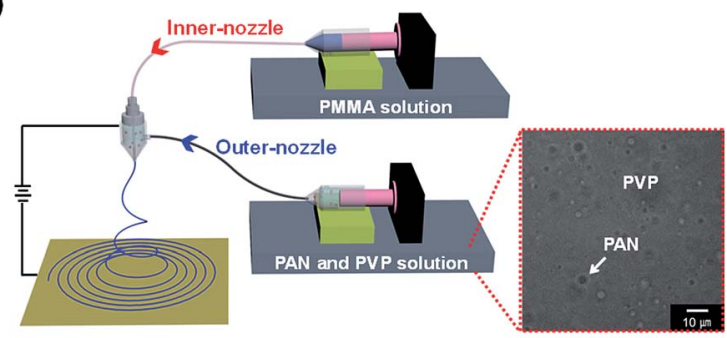

(b)

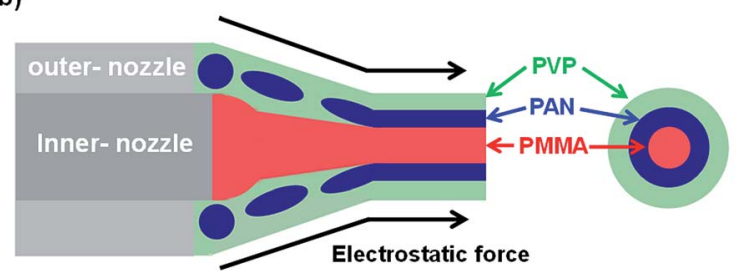

Fig. 1 (a) Illustrative diagram of dual-nozzle co-electrospinning process (inset: phase separated mixed polymer solution). (b) Formation mechanism of three-layered polymer nanofibers through dual-nozzle co-electrospinning. 
PVP) can serve as a template for the core polymer (PMMA) leading to cable-type structures. ${ }^{27,28}$

More specifically, the formation mechanism of three-layered electrospun nanofiber is suggested as following (Fig. 1b). First, a stable Taylor cone is formed, when the proper combination of optimum electrospinning conditions. Then, three-layered coaxial jet is formed through high voltage applying between outer-part of metallic dual-nozzle and ground. The jet is subsequently stretched by electrostatic forces to generate threelayered co-axial nanofibers. The elongation of the sheath is mainly driven by electrostatic repulsions of the surface charges, during the spinning process. Moreover, rapid stretching of the sheath can cause phase separation of the shell layer (PAN/PVP) and strong viscous stress, which passes on to the PMMA core. Tangential to the jet line, the shear stress stretch the PMMA phase and elongation it along with the sheath solution via mechanism such as viscous dragging and contact friction.

The as prepared nanofibers formed three layered (PMMA: first layer; PAN: second layer; PVP: third layer) with $c a .200 \mathrm{~nm}$ diameter (Fig. 2a-c). The electrospun three-layered nanofibers were then carbonized at a rate of $5^{\circ} \mathrm{C} \mathrm{min}^{-1}$ and maintained for

(a)

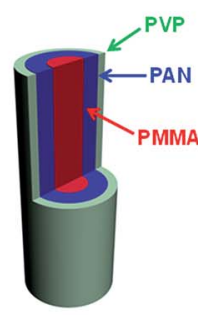

Three-layered polymer nanofiber
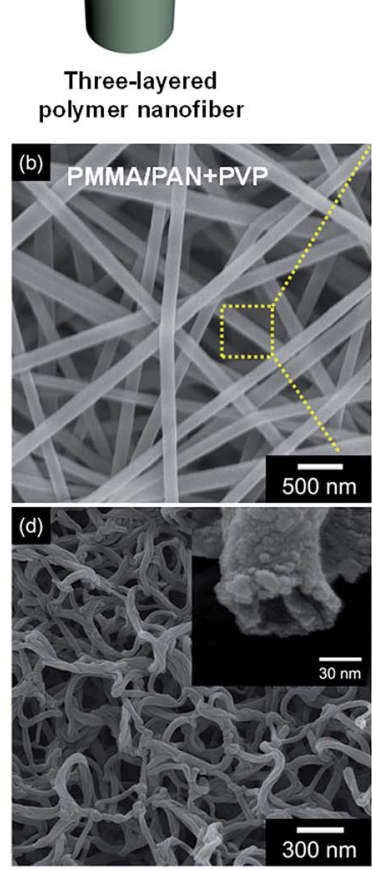

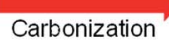

Carbonization

Porous carbon nanotube
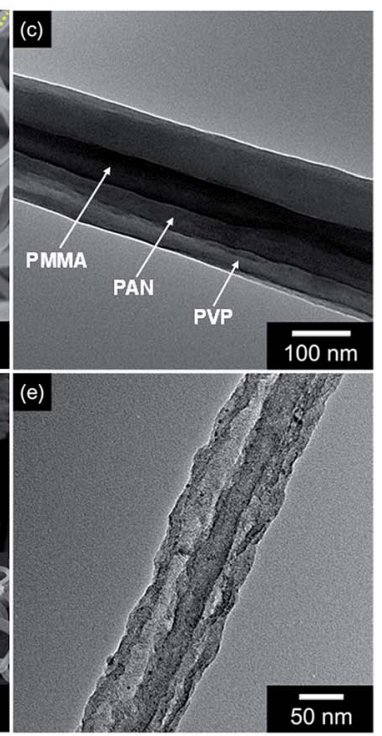

Fig. 2 (a) Schematic diagram of the sequential fabrication steps for highly porous carbon nanotubes. (b) Field-effect scanning electron microscopy (FE-SEM) and (c) transmission electron microscopy (TEM) images of the electrospun nanofiber composed of PMMA, PAN, and PVP layers. (d) Low- and high-resolution (inset) FE-SEM and (e) TEM images of highly porous carbon nanotubes (PCNT_4) originated from PMMA, PAN, and PVP layered electrospun nanofibers.
$1 \mathrm{~h}$ at $800{ }^{\circ} \mathrm{C}$ under Ar flow. During this process, PVP and PMMA decomposed and PAN transferred to graphite carbon. The as fabricated porous carbon nanotubes (denoted as PCNT_4) exhibited $c a .80 \mathrm{~nm}$-diameter and $c a .7 \mathrm{~nm}$-thickness with small pores generation in the carbon structure (Fig. $2 \mathrm{~d}$ and e).

Moreover, other carbon nanotubes from different composition of co-axial nanofibers were also suggested to confirm the effect of each layer (PMMA and PVP) for formation of carbon architectures (Fig. 3). First, carbon nanotubes originated from without PVP layer (PMMA/PAN) are suggested in the Fig. $3 \mathrm{~b}$ and e. The electrospun core-shell nanofibers exhibited $c a .380 \mathrm{~nm}$ diameter that is larger than that of three-layered nanofibers (ca. $200 \mathrm{~nm}$ ). The following carbon nanotubes (denoted as PCNT_2) also displayed larger diameter (ca. $180 \mathrm{~nm})$ than that of highly porous carbon nanotubes $(c a .80 \mathrm{~nm})$. Second, carbon nanotubes from mineral oil as core phase (mineral oil/PAN and PVP) are also demonstrated. The electrospun nanofibers represented three-layered co-axial architecture with $c a .230 \mathrm{~nm}$ diameter, similar size to three-layered nanofibers (Fig. 3c). However, the morphology of the carbonized nanotubes, denoted as PCNT_3, revealed uniform surface architecture without roughness and higher thickness (ca. $20 \mathrm{~nm}$ ) than that of PMMA core nanofiber derived carbon (Fig. 3f). Additionally, co-axial nanofibers composed of mineral oil and PAN also suggested with ca. $400 \mathrm{~nm}$-diameter and following carbonized nanotubes (denoted as PCNT_1) revealed $c a .210 \mathrm{~nm}$ of diameter without small pores in the structure (Fig. 3a and d). Therefore, the PVP layer cause reducing diameter of nanofibers and PMMA generate small pores in the carbon structure.

\subsection{Characterization of highly porous carbon nanotubes}

To confirm the microstructure change of the carbon nanotubes with different components, Brunauer-Emmett-Teller (BET) and Barrett-Joyner-Halenda (BJH) measurements were performed. Fig. 4a present the $\mathrm{N}_{2}$ adsorption/desorption isotherms obtained using the BET method for the various carbon nanotubes. The surface area increased with emerging small pores in the structure and decreasing diameter of nanotubes as followings: $18.8 \mathrm{~m}^{2} \mathrm{~g}^{-1}$ for PCNT_1 (oil/PAN); $886.2 \mathrm{~m}^{2} \mathrm{~g}^{-1}$ for PCNT_2 (PMMA/PAN); $43.9 \mathrm{~m}^{2} \mathrm{~g}^{-1}$ for PCNT_3 (oil/PAN + PVP); $1023.9 \mathrm{~m}^{2} \mathrm{~g}^{-1}$ for PCNT_4 (PMMA/PAN + PVP). In particular, this rapid increment in the surface area was caused by the emergence small pores in the carbon structure with adding PMMA core layer rather than diminishing diameter by using PVP shell layer; the surface area of PCNT_2 $\left(886.2 \mathrm{~m}^{2} \mathrm{~g}^{-1}\right)$ was $c a .20$ times larger than that of the PCNT_3 $\left(43.9 \mathrm{~m}^{2} \mathrm{~g}^{-1}\right)$. Therefore, the small pores originated from decomposing of PMMA core layer had a significant effect on the surface area of carbon nanostructure rather than decreasing diameter from PVP addition. Moreover, pore distribution of different carbon nanotubes was suggested through BJH method as demonstrated in Fig. 4b. The peaks at $1.9 \mathrm{~nm}$ and $2.3 \mathrm{~nm}$ emerged with PMMA core addition. Therefore, these peaks are originated from porous structure that caused to increase surface area of carbon nanotubes drastically.

The chemical composition of the PCNTs was also changed with containing PMMA core phase in the electrospun nanofiber. 

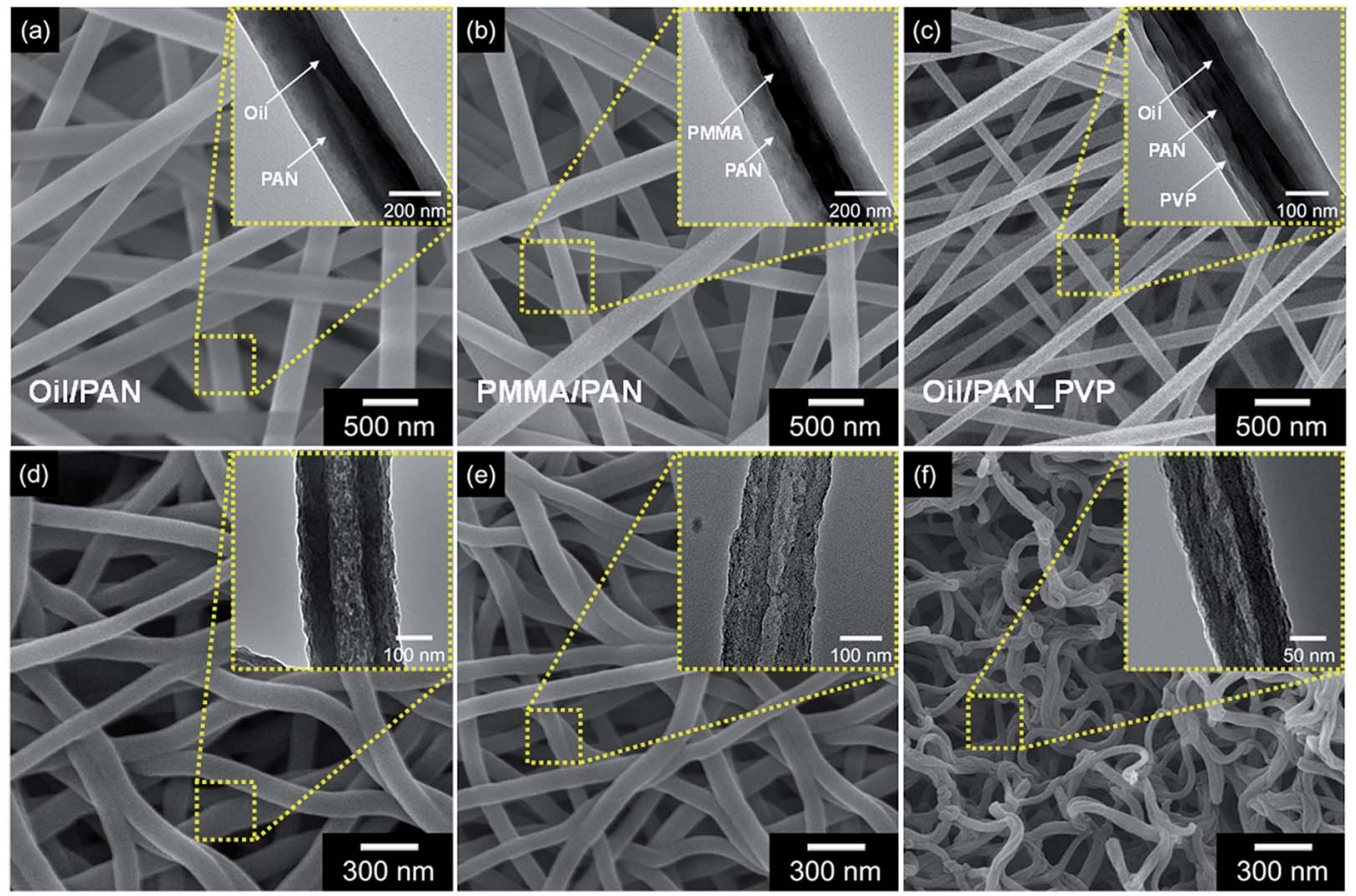

Fig. 3 FE-SEM and TEM (inset) images of electrospun nanofibers composed of (a) mineral oil and PAN, (b) PMMA and PAN, and (c) mineral oil, PAN, and PVP layers. FE-SEM and TEM (inset) images of carbon nanotubes originated from (d) mineral oil and PAN (PCNT_1) layered, (e) PMMA and PAN (PCNT_2) layered and (f) mineral oil, PAN, and PVP (PCNT_3) layered electrospun nanofibers.

(a)

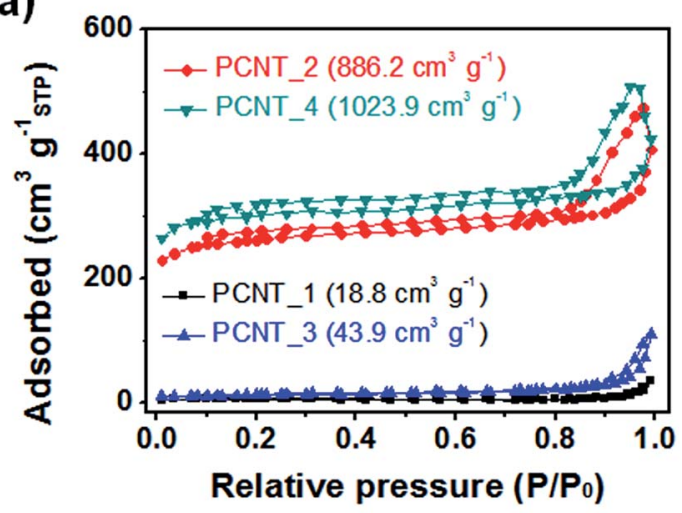

(b)

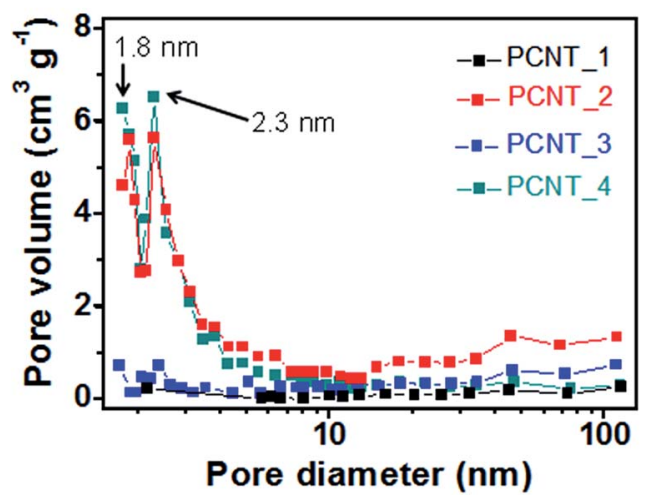

Fig. 4 (a) Nitrogen adsorption-desorption and (b) pore size distribution curves for different PCNTs: black: PCNT_1; red: PCNT_2; blue: PCNT_3; green: PCNT_4 (STP represents standard temperature and pressure).
Fig. 5 suggests high-resolution X-ray photoelectron spectroscopy (XPS) spectra for the $\mathrm{C} 1 \mathrm{~s}$ region around $285 \mathrm{eV}$ for each PCNT. First, PCNTs without PMMA core phase (PCNT_1 and PCNT_3) were deconvoluted into four components as follows: the $284.3 \mathrm{eV}$ peak corresponds to $\mathrm{C}=\mathrm{C}$ bonds, the $285.3 \mathrm{eV}$ peak corresponds to $\mathrm{C}-\mathrm{C}$ bonds, the $286.6 \mathrm{eV}$ corresponds to $\mathrm{C}-\mathrm{O}$ bonds, and ca. $290 \mathrm{eV}$ corresponds to shake-up satellite graphite carbon. Second, PCNTs with PMMA core phase (CPNT_2 and CPNT_4) were also deconvoluted into four components: $\mathrm{C}=\mathrm{C}$, $\mathrm{C}-\mathrm{C}, \mathrm{C}-\mathrm{O}$, and $\mathrm{pi}=\mathrm{pi}^{*}$ bonds. However, the peak for $\mathrm{C}-\mathrm{O}$ at
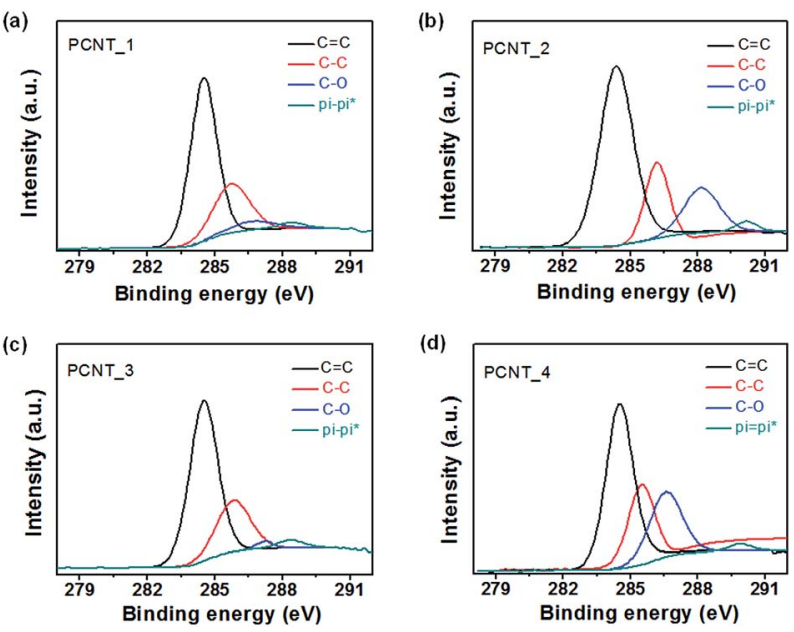

Fig. 5 X-ray photoelectron spectroscopy (XPS) $C$ 1s patterns of different PCNTs: (a) PCNT_1, (b) PCNT_2, (c) PCNT_3, and (d) PCNT_4. 
$286.6 \mathrm{eV}$ drastically increased owing to heat decomposition of PMMA core phase with small pore formation in the carbon surface during carbonization process.

\subsection{Electrochemical performance of highly porous carbon nanotubes}

To assess the potential of the porous carbon nanotubes as electrode materials for supercapacitors (SCs), the electrochemical properties were investigated using a three-electrode cell, specifically, a $1 \mathrm{M} \mathrm{H}_{2} \mathrm{SO}_{4}$ aqueous electrolyte with $\mathrm{Pt}$ counter electrode and an $\mathrm{Ag} / \mathrm{AgCl}$ reference electrode. First, cyclic voltammetry (CV) curves were measured at a scan rate of $50 \mathrm{mV} \mathrm{s}^{-1}$ in the voltage from $0 \mathrm{~V}$ to $1 \mathrm{~V}$ for different carbon nanotube electrodes (Fig. 6a). The CV curves display rectangular-like shape on account of double layer formation at the electrode-electrolyte interface and no redox reaction during charge/discharge reactions. The area under the CV curves increased with formation of small pores and decrease of diameters originated from decomposition of PMMA and PVP layer in the nanofiber structure. In particular, the current density of PCNT_4 was $11.25 \mathrm{~A} \mathrm{~g}^{-1}$ that was $c a$. 10-fold large than that of PCNT_1 (without small pores and diminishing diameter). In addition, increasing amount of current density of PCNT_3 (with only small pores) was higher than that of PCNT_2 (with only small diameter) owing to small pores more enhanced active surface area between the electrode and ions of electrolyte.

Furthermore, PCNT_4 also displayed rectangular-like CV curves for increasing scan rate (10 to $100 \mathrm{mV} \mathrm{s}^{-1}$ ) without area under the $\mathrm{CV}$ curves; this indicated ideal capacitive behavior and fast charge-discharge properties (Fig. 6b). The rectangular- like shape at the higher scan rate is due to the presence of small pores. The solvated cation $\left(\mathrm{H}_{3} \mathrm{O}^{+}\right)$and anion $\left(\mathrm{SO}_{4}{ }^{2-}\right)$ in $\mathrm{H}_{2} \mathrm{SO}_{4}$ solution have ion sizes of $0.42 \mathrm{~nm}$ and $0.53 \mathrm{~nm}$, respectively. ${ }^{43,44}$ These ions can easily diffuse through the small pores with size larger than $1 \mathrm{~nm}$. On the other hand, other carbon nanotubes without small pores presented diminishing area under the CV curves with increasing scan rate as shown in the Fig. S2. $\dagger$

Galvanostatic charge-discharge measurements were carried out on the different electrodes to obtain more detailed information related to the specific capacitance. The galvanostatic curves of PCNT_4 reasonably symmetric and linear over time with enhancing current density, further demonstrating ideal

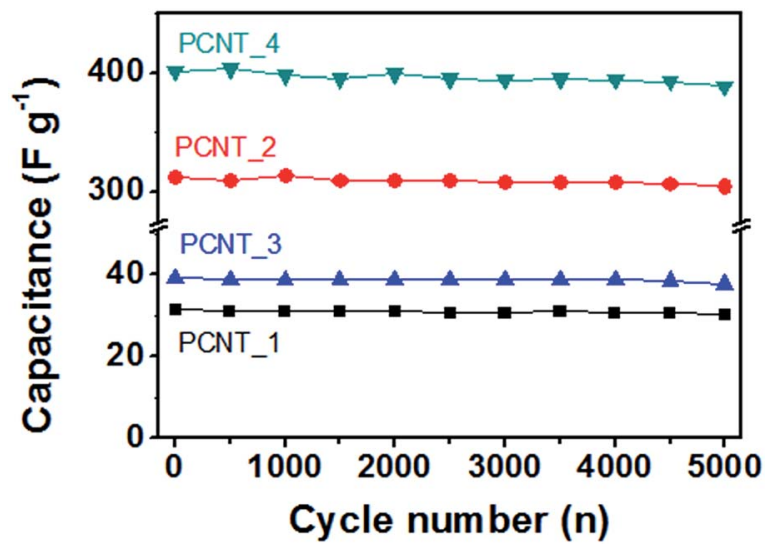

Fig. 7 Cycling performance of the different PCNTs at $2 \mathrm{~A} \mathrm{~g}^{-1}$ of current density (black: PCNT_1; red: PCNT_2; blue: PCNT_3; green: PCNT_4). (a)
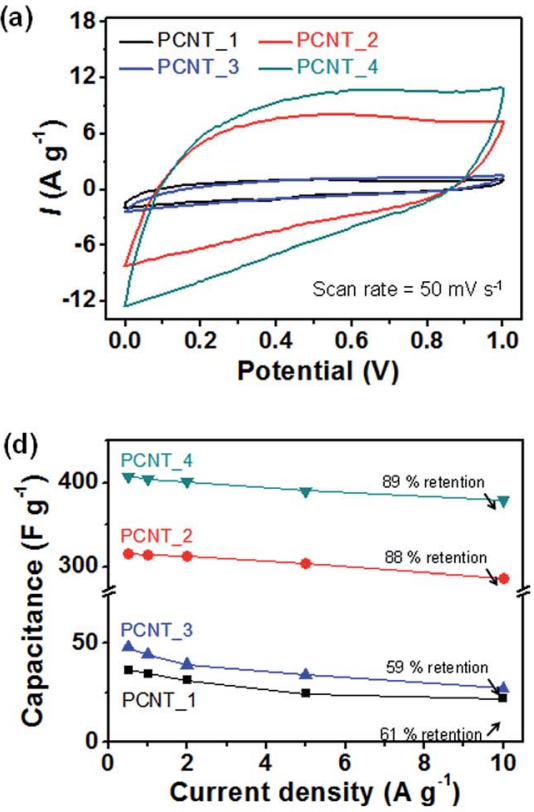

(b)

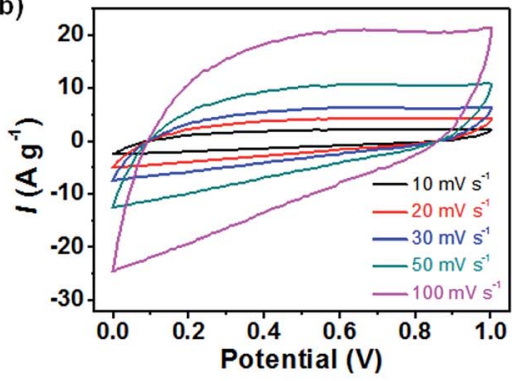

(e)

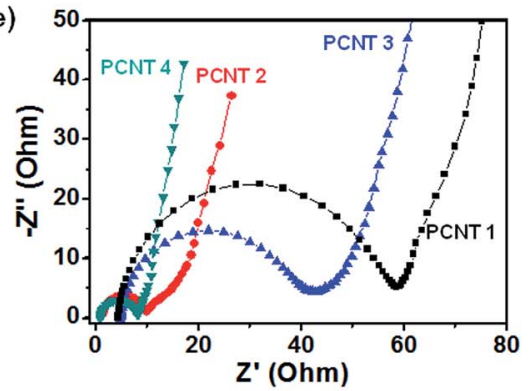

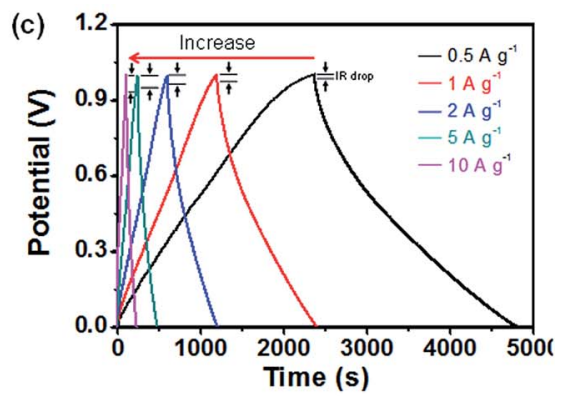

(f)

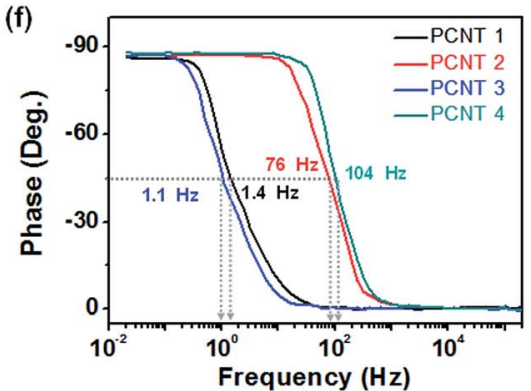

Fig. 6 (a) CV curves of various PCNTs at $50 \mathrm{mV} \mathrm{s}^{-1}$ of voltage scan rate (black: PCNT_1; red: PCNT_2; blue: PCNT_3; green: PCNT_4). (b) CV curves of PCNT_4 with different scan rates $\left(10-100 \mathrm{mV} \mathrm{s}^{-1}\right.$ ). (c) Galvanostatic charge-discharge curves of PCNT_4 with diverse current densities $\left(0.5-10 \mathrm{~A} \mathrm{~g}^{-1}\right.$ ). (d) Calculated specific capacitance of different PCNTs from galvanostatic charge/discharge curves. (e) Nyquist plot and (f) Bode phase plot of different electrodes (frequency: $200 \mathrm{kHz}$ to $20 \mathrm{mHz}$ ) (black: PCNT_1; red: PCNT_2; blue: PCNT_3; green: PCNT_4). 
Table 1 Summary of representative carbons for supercapacitor electrode materials

\begin{tabular}{|c|c|c|c|c|}
\hline Material & Synthesis & Specific capacitance $\left(C_{\mathrm{G}}\right)$ & Cycle stability & Reference \\
\hline $\mathrm{MnO}_{2} / \mathrm{CNF} / \mathrm{rGO}$ & Electrospinning/Hummer's method & $174 \mathrm{~F} \mathrm{~g}^{-1}$ & $91 \%$ (500 cycles) & 2 \\
\hline Hollow carbon fibers & Cotton carbonization & $355 \mathrm{~F} \mathrm{~g}^{-1}$ & $92.4 \%$ (4000 cycles) & 8 \\
\hline Carbon nanofibers & Electrospinning & $130.7 \mathrm{~F} \mathrm{~g}^{-1}$ & - & 30 \\
\hline Porous carbon fibers & Electrospinning/activation & $197 \mathrm{~F} \mathrm{~g}^{-1}$ & - & 40 \\
\hline PCNT_4 & Dual-nozzle co-electrospinning & $401 \mathrm{~F} \mathrm{~g}^{-1}$ & $89 \%$ (5000 cycles) & This work \\
\hline
\end{tabular}

capacitive behavior and rapid charge-discharge characteristics (Fig. 6c). However, other carbon nanotubes without small pores displayed slightly asymmetric shapes with increasing current density (Fig. S3†). In addition, the IR drop of curves increased with enhancing current density from $0.004 \mathrm{~V}\left(0.5 \mathrm{~A} \mathrm{~g}^{-1}\right)$ to $0.08 \mathrm{~V}\left(10 \mathrm{~A} \mathrm{~g}^{-1}\right)$.

Fig. $6 \mathrm{~d}$ shows the specific capacitance $\left(C_{\mathrm{G}}\right)$ calculated from the galvanostatic charge-discharge curves as a function of the current density. The calculated specific capacitance of the electrodes at $2 \mathrm{~A} \mathrm{~g}^{-1}$ as follows: $31.1 \mathrm{~F} \mathrm{~g}^{-1}$ for PCNT_1; $313 \mathrm{~F} \mathrm{~g}^{-1}$ for PCNT $\_2 ; 39.2 \mathrm{~F} \mathrm{~g}^{-1}$ for PCNT_3; $401 \mathrm{~F} \mathrm{~g}^{-1}$ for PCNT_4. As the current density increased from $0.5 \mathrm{~A} \mathrm{~g}^{-1}$ to $10 \mathrm{~A} \mathrm{~g}^{-1}$, the capacitance retention of the PCNT_4 (89\%) was larger than that without small pores (PCNT_1: 61\%; PCNT_2: 59\%).

Electrochemical capacitance spectra (EIS) measurements were used to further investigate the electrochemical and structural characteristics of the electrodes. Fig. 6e show the Nyquist plot of the electrodes with $1 \mathrm{M}-\mathrm{H}_{2} \mathrm{SO}_{4}$ electrolyte. A change of the midrange frequency impedances in electrodes gives rise to visible knee frequency, characteristics of transition from frequency-dependent diffusion resistance to pure capacitive behavior. $^{45}$ At high frequencies, the electrode behaves like resistance $(R)$. The intercept and size of the semicircle are related to the equivalent series resistance (ESR) and size of the semicircle are related to the equivalent series resistance (ESR) and charge transfer resistance at the interface between the electrode and electrolyte $\left(R_{\mathrm{ct}}\right)$, respectively. The ESR and $R_{\mathrm{ct}}$ also reduced by the small pores formation and decreasing diameter as following: $4.38 \Omega(\mathrm{ESR}) / 54.06 \Omega\left(R_{\mathrm{ct}}\right)$ for PCNT_1, $1.38 \Omega$ $(\mathrm{ESR}) / 8.52 \Omega\left(R_{\mathrm{ct}}\right)$ for PCNT_2, $5.09 \Omega(\mathrm{ESR}) / 37.33 \Omega\left(R_{\mathrm{ct}}\right)$ for PCNT_3, $0.95 \Omega(\mathrm{ESR}) / 7.13 \Omega\left(R_{\mathrm{ct}}\right)$ for PCNT_4, respectively.

Fig. of displays the Bode phase plot of the electrodes. The capacitor response frequency for diverse electrodes at a phase angle of $-45^{\circ}$ was as follows: $1.4 \mathrm{~Hz}$ for PCNT_1; $76 \mathrm{~Hz}$ for PCNT $\_2 ; 1.1 \mathrm{~Hz}$ for PCNT_3; $104 \mathrm{~Hz}$ for PCNT_4. Therefore, the calculated relaxation time constant $\left(\tau_{0}\right)$ that indicates pore capacity behavior and stored energy accessibility of frequencies blow this frequency was calculated to be $0.71 \mathrm{~s}$ for PCNT_1, 13 $\mathrm{ms}$ for PCNT_2, $0.91 \mathrm{~s}$ for PCNT_3, and $9.6 \mathrm{~ms}$ for PCNT_4, respectively. At low frequencies ( $0.2 \mathrm{~Hz}$ for PCNT $\_1,10.1 \mathrm{~Hz}$ for PCNT_2, $0.16 \mathrm{~Hz}$ for PCNT_3, and $12.6 \mathrm{~Hz}$ for PCNT_4), the phase angles for electrodes are $c a .-90^{\circ}$ which is close to ideal for capacitor electrodes.

Moreover, the cycle stability of the electrodes suggested as a function of the cycle number at a $2 \mathrm{~A} \mathrm{~g}^{-1}$ current density over the constant voltage range from 0 to $1 \mathrm{~V}$ (Fig. 7). All of carbon nanotubes displayed large retention capacitance ( $c a .97 \%)$ after 5000 cycles (96\% for PCNT_1; 97\% for PCNT_2; 96\% for PCNT_3; 97\% for PCNT_4) on account of electron double layer energy storage mechanism of carbon material. In addition, energy storage ability of the PCNT_4, as supercapacitor electrode materials, is larger than that of other carbon materials (Table 1).

\section{Conclusions}

In summary, highly-porous carbon nanotubes were fabricated though facile dual-nozzle co-electrospinning technique. To the best of our knowledge, this is the first demonstration of the fabrication of highly porous carbon nanotubes based on dualnozzle co-electrospinning process. This porous carbon nanotubes exhibited small pores $(c a .2 \mathrm{~nm})$ in the carbon surface owing to decomposing of PMMA core phase during carbonization. Moreover, the porous carbon nanotubes exhibited small diameter originated from PVP shell layer. The resulting porous carbon nanotubes were used as electrode to prepare supercapacitors (SCs) with enhanced specific capacitance and rate capability. The small pores in the carbon structure were critical in improving the properties of SCs owing to it enlarged active surface area between carbon and ions of electrolyte. Thus, this study demonstrated an effective method to fabricate highly porous 1D carbon nanomaterials for energy storage applications.

\section{Notes and references}

1 Q. Wang, J. Yan and Z. Fan, Energy Environ. Sci., 2016, 9, 729. 2 O. S. Kwon, T. Kim, J. S. Lee, S. J. Park, H.-W. Park, M. Kang,

J. E. Lee, J. Jang and H. Yoon, Small, 2013, 9, 248.

3 J. S. Lee, D. H. Shin, J. Jun, C. Lee and J. Jang, ChemSusChem, 2014, 7, 16676.

4 Y. Shim and H. J. Kim, ACS Nano, 2010, 4, 2345.

5 O. N. Kalugin, V. V. Chaban, V. V. Loskutov and O. V. Prezhdo, Nano Lett., 2008, 8, 2126.

6 S. Hu, S. Zhang, N. Pan and Y.-L. Hsieh, J. Power Sources, 2014, 270, 106.

7 L. Fu, K. Tang, K. Song, P. A. Van Aken, Y. Yu and J. Maier, Nanoscale, 2014, 6, 1384.

8 S. Wang, Z. Ren, J. Li, Y. Ren, L. Zhao and J. Yu, RSC Adv., 2014, 4, 31300.

9 Y. Bai, Z.-H. Huang and F. Kang, Carbon, 2014, 66, 705. 
10 Y. Yu, L. Gu, C. Zhu, P. A. V. Aken and J. Maier, J. Am. Chem. Soc., 2009, 131, 15984.

$11 \mathrm{~J} . \mathrm{Li}, \mathrm{Z}$. Ren, Y. Ren, L. Zhao, S. Wang and J. Yu, RSC Adv., 2014, 4, 35789.

12 X. Mao, A. Hatton and G. C. Rutledge, Curr. Org. Chem., 2013, 17, 1390.

13 T. H. Hwang, Y. M. Lee, B.-S. Kong, J.-S. Seo and J. W. Choi, Nano Lett., 2012, 12, 802.

14 Y. Liang, D. Wu and R. Fu, Sci. Rep., 2013, 3, 1119.

15 Y. Yang, A. Centrone, L. Chen, F. Simeon, T. A. Hatton and G. C. Rutledge, Carbon, 2011, 49, 3395.

16 C. Niu, J. Meng, X. Wang, C. Hang, M. Yan, K. Zhao, X. Xu, W. Ren, Y. Zhao, L. Xu, Q. Zhang, D. Zhao and L. Mai, Nat. Commun., 2015, 6, 7402.

17 D. Grafahrend, K.-H. Heffels, M. V. Beer, P. Gasteier, M. Moller, G. Boehm, P. D. Dalton and J. Groll, Nat. Mater., 2011, 10, 67.

18 S. Zhang, M. A. Greenfield, A. Mata, L. C. Palmer, R. Bitton, J. R. Mantei, C. Aparicio, M. O. Cruz and S. I. Stupp, Nat. Mater., 2010, 9, 594.

19 Z. Zhang, X. Li, C. Wang, L. Wei, Y. Liu and C. Shao, J. Phys. Chem. C, 2009, 113, 19397.

20 S. M. Park and D. S. Kim, Adv. Mater., 2015, 27, 1682.

21 N. G. Sahoo, S. Rana, J. W. Cho, L. Li and S. H. Chan, Prog. Polym. Sci., 2010, 35, 837.

22 C. A. Bonino, K. Efimenko, S. I. Jeong, M. D. Krebs, E. Alsberg and S. A. Khan, Small, 2012, 8, 1928.

23 X. Lu, C. Wang and Y. Wei, Small, 2009, 5, 2349.

24 S. W. Lee, H. J. Lee, J. H. Choi, W. G. Koh, J. M. Myoung, J. H. Hur, J. J. Park, J. H. Cho and U. Jeong, Nano Lett., $2010,10,347$.

25 A. V. Bazilevsky, A. L. Tarin and C. M. Megaridis, Langmuir, 2007, 23, 2311.

26 J. S. Lee, O. S. Kwon, S. J. Park, E. Y. Park, S. A. You, H. Yoon and J. Jang, ACS Nano, 2011, 5, 7992.
27 Y. Yu, L. Gu, C. Wang, A. Dhanabalan, P. A. van Akenm and J. Maier, Angew. Chem., Int. Ed., 2009, 48, 6485.

28 J. H. Yu, S. V. Fridrikh and G. C. Rutledge, Adv. Mater., 2004, 16, 1562.

29 J. E. Diaz, A. Barrero, M. Marquez and I. G. Loscertales, Adv. Funct. Mater., 2006, 16, 2110.

30 B.-H. Kim, K. S. Yang, Y. A. Kim, Y. J. Kim, B. An and K. Oshida, J. Power Sources, 2011, 196, 10796.

31 J. Jun, J. S. Lee, D. H. Shin, S. G. Kim and J. Jang, Nanoscale, 2015, 7, 16026.

32 Y. J. Yun, W. G. Hong, W.-J. Kim, Y. Jun and B. H. Kim, Adv. Mater., 2013, 25, 5701.

33 C. Lei, F. Markoulidis, Z. Ashitaka and C. Lekakou, Electrochim. Acta, 2013, 92, 183.

34 K. Nakagawa, S. R. Mukai, K. Tamura and H. Tamon, Chem. Eng. Res. Des., 2007, 85, 1331.

35 M. Toupin, D. Belanger, I. R. Hill and D. Quinn, J. Power Sources, 2005, 140, 203.

36 E. Frackowiak and F. Beguin, Carbon, 2001, 39, 937.

37 J. Chmiola, C. Largeot, P.-L. Taberna, P. Simon and Y. Gogotsi, Science, 2010, 328, 480.

38 W. Li, Q. Yue, Y. Deng and D. Zhao, Adv. Mater., 2013, 25, 5129.

39 C. Liang, Z. Li and S. Dai, Angew. Chem., Int. Ed., 2008, 47, 3696.

40 D. Lee, J.-Y. Jung, M.-J. Jung and Y.-S. Lee, Chem. Eng. J., 2015, 263, 62.

41 J. D. Hartgerink, E. Beniash and S. I. Stupp, Science, 2001, 294, 1684.

42 Z. Dong, S. J. Kennedy and Y. Wu, J. Power Sources, 2011, 196, 4886.

43 M. Endo, T. Maeda, T. Takeda, Y. J. Lim, K. Koshiba, H. Hara and M. S. Dresselhaus, J. Electrochem. Soc., 2001, 148, A910.

44 L. Eliad, G. Salitra, A. Soffer and D. Aurbach, J. Phys. Chem. B, 2001, 105, 6880.

45 J. Zhang and X. S. Zhao, ChemSusChem, 2012, 5, 818. 